\title{
Carbon Nitrogen Co-Doped P25: Parameter Study on Photodegradation of Reactive Red 4
}

\author{
M. S. Azami ${ }^{1, a}$, W. I. Nawawi ${ }^{2}$, M. A. M. Ishak ${ }^{2}$, K. Ismail ${ }^{1}$, Z. Ahmad ${ }^{2}$ and Ali H. Jawad ${ }^{2}$ \\ ${ }^{1}$ Faculty of Applied Sciences, Universiti Teknologi MARA, 40450 Shah Alam, Selangor, Malaysia \\ ${ }^{2}$ Faculty of Applied Sciences, Universiti Teknologi MARA, 02600 Arau, Perlis, Malaysia
}

\begin{abstract}
Photocatalytic degradation rate of reactive red 4 (RR4) using carbon coated nitrogen doped $\mathrm{TiO}_{2}\left(\mathrm{C} \mathrm{N}\right.$ co-doped $\left.\mathrm{TiO}_{2}\right)$ in photocatalysis process is main goal on this research. The main operating the parameters such as effect of initial dye concentration, catalyst loading, aeration flow rate and initial $\mathrm{pH}$ on degradation of RR4 under $45 \mathrm{~W}$ fluorescent lamp was investigated. photocatalytic activity of RR4 dye decreased with increasing RR4 dye concentration. The optimum loading is around $0.04 \mathrm{~g}$ and optimum aeration rate is about 25 $\mathrm{mL} \min ^{-1}$ of $\mathrm{C} \mathrm{N}$ co-doped $\mathrm{TiO}_{2}$. Effect of $\mathrm{pH}$ was conducted based on the optimum loading and conclude that the photocatalytic degradation of RR4 became faster at $\mathrm{pH} 2-7$. For the future work, the modification of doping with others element like non-metal or metal with $\mathrm{C} \mathrm{N}$ co-doped $\mathrm{TiO}_{2}$ can be enhanced toward the higher efficieny of photodegradation under visible light. Moreover, the immobilized technique can be used in future to overcome the difficulty of filtration on suspension.
\end{abstract}

\section{Introduction}

Heterogenous photocatalysis is the process basically based on the oxidation process of photogenerated holes with hydroxide ion or water to form hydroxyl radical. This hydroxyl radical which is highly oxidizing agents will oxidized the organic wastewater pollutants into harmless product. The combination between semiconductor photocatalyst and light sources is the key process of photodegradation. Among of the semiconductor, titanium dioxide $\left(\mathrm{TiO}_{2}\right)$ is the most popular and widely used by researchers due to its chemical stability, low cost, atoxic, capability for the reusable and its high photocatalytic activity [1-4]. This material consist a wide band gaps between $3.0 \mathrm{eV}$ to 3.2 $\mathrm{eV}$ which require the UV light irradiation which means that only (4-6\%) of sunlight has the required energy to activate the photocatalyst [5]. Thus, the doping techniques have been explored to enhance the photocatalysis toward visible light. The non-metal element $(\mathrm{N}, \mathrm{C}, \mathrm{S}, \mathrm{F}$ and $\mathrm{P})$ have been discovered as great potential for enhance the visible light in $\mathrm{TiO}_{2}$ materials [6-8]. Among all the nonmetal doped $\mathrm{TiO}_{2}$ materials, nitrogen doped carbon coated $\mathrm{TiO}_{2}$ have been discerned to exhibit superior photocatalytic activity under visible light irradiation [9]. Several advantages of carbon coated can be listed such as improved the adsorption of pollutants, improvement of anatase crystalline structure, better rate of sedimentation of the photocatalyst particles and suppression of phase transformation from anatase to rutile at high temperature [10]. Meanwhile, nitrogen doped $\mathrm{TiO}_{2}$ can

\footnotetext{
${ }^{a}$ Corresponding author : saifulddinazami@gmail.com
} 
be supreme potential toward the visible-light absorption due to metastable center formation, small ionization energy and its comparable atomic size in oxygen [11]. In this work, The C, N co-doped P25 sample was already preparad by Nawawi [10]. Subsequent experiments were conducted to investigate the effect of parameter of $\mathrm{C} \mathrm{N}$ co-doped $\mathrm{TiO}_{2}$ on the photodegradation of RR4. The effect of initial dye concentration, catalyst loading, aeration flow rate and initial $\mathrm{pH}$ on degradation of RR4 was investigated.

\section{Experimental}

\subsection{Materials}

C N co-doped $\mathrm{TiO}_{2}$ preparad by Nawawi [10], Sodium Hydroxide $(\mathrm{NaOH})$, Hydrochloric acid (HCl), Potassium Chloride (KCl), Reactive red (RR4) dye or commonly known as Cibacron Brilliant Red (Colour Index Number: 18105, chemical formula: $\mathrm{C}_{32} \mathrm{H}_{23} \mathrm{CIN}_{8} \mathrm{Na}_{4} \mathrm{O}_{14} \mathrm{~S}_{4}$, molecular weight: $995.23 \mathrm{~g}$ $\mathrm{mol}^{-1}, \lambda$ max: $517 \mathrm{~nm}$ ). Ultra-pure water was used to prepare all solutions in this work, 45 Watt fluorescent lamp, aeration pump.

\subsection{Methods}

\subsubsection{Effect of initial dye concentration on the photocatalytic efficiency of the modified photocatalyst}

Four sets of RR4 dye with different concentrations $\left(5,10,30\right.$ and $\left.60 \mathrm{mg} \mathrm{L}^{-1}\right)$ were used as the model pollutant in order to study the effect of concentration of the RR4 dye on the photocatalytic efficiency of the modified photocatalyst. $0.024 \mathrm{~g}$ of a selected modified photocatalyst sample was dispersed in $20 \mathrm{ml}$ of RR4 dye solution at different concentrations under ultrasonic sonication for 30 seconds. The respective aqueous suspension of the catalyst within the dye solutions was then irradiated with 45 Watt compact visible light fluorescent lamp for 1 hour. Aliquots were taken at every 15 minutes time interval and the solution was filtered through a $0.45 \mu \mathrm{m}$ cellulose acetate membrane filter to remove the catalyst particles. The concentration of the remaining RR4 dye was measured spectrophotometrically using HACH DR2000 spectrophotometer.

\subsubsection{The Effect of the photocatalyst loading}

A series of $20 \mathrm{~mL}$ of $30 \mathrm{mg} \mathrm{L}^{-1} \mathrm{RR} 4$ dye solution with respective loading of $0.012,0.024,0.04$, and $0.08 \mathrm{~g}$ of the optimum photocatalyst were prepared separately and dispersed under ultrasonic vibration for 30 seconds. Each aqueous suspension was then irradiated with 45 Watt visible light fluorescent lamp for one hour. The remaining RR4 in the sample solution was measured using HACH DR2000 spectrophotometer after every 15 minutes interval of irradiation. The percent degradation of RR4 dye solution was plotted against the dosage of the photocatalyst.

\subsubsection{The effect of the aeration flow rate}

Various aeration flow rates were applied to the system since air can provide oxygen for the degradation of RR4 dye. For the effect of aeration study, the flow rate of $0,15,25,50$ and $100 \mathrm{~mL}$ min-1 was respectively supplied into the systems containing the mixture of $0.024 \mathrm{~g}$ of the optimum photocatalyst in $20 \mathrm{ml}$ of $30 \mathrm{mg} \mathrm{L}^{-1} \mathrm{RR} 4$ dye solution. The RR4 solution was irradiated with a 45 Watt fluorescent lamp at each respective aeration rate. 


\subsubsection{The effect of initial $\mathrm{pH}$ values of the RR4 dye solutions}

For this experiment, a series of $20 \mathrm{~mL}, 30 \mathrm{mg} \mathrm{L}^{-1} \mathrm{RR} 4$ dye solutions at different initial $\mathrm{pH}$ values were used. The $\mathrm{pH}$ of each solution was adjusted to values of about 2, 4, 7 and 10 respectively before being photocatalytically decolorized using $0.024 \mathrm{~g}$ of optimum photocatalyst under a $45 \mathrm{~W}$ fluorescent lamp. The $\mathrm{pH}$ values of every solution were adjusted using $1 \mathrm{M} \mathrm{NaOH}$ and $1 \mathrm{M} \mathrm{HCl}$ solutions

\subsubsection{Determination of point of the zero charge ( $p H z p c)$ for the unmodified and modified photocatalyst}

$\mathrm{pH}$ of the zero charge (pHzpc) for photocatalysts were determined according to the procedures outlined by Machado and Santana [12]. A series of $50 \mathrm{~mL}$ ultra-pure water with different $\mathrm{pH}$ ranging from $\mathrm{pH} 2$ to 10 was prepared. The $\mathrm{pH}$ of the solution was adjusted using $1 \mathrm{M} \mathrm{NaOH}$ and $1 \mathrm{M} \mathrm{HCl}$ solutions. $0.01 \mathrm{~g}$ of the unmodified and modified catalyst was added into each solution followed by addition of $10 \mathrm{ml}$ of $0.1 \mathrm{M} \mathrm{KCl}$. The solutions were stirred and the final $\mathrm{pH}$ values of the solutions were recorded after 24 hours of stirring. The discrepancies of the $\mathrm{pH}$ were obtained by subtracting the initial $\mathrm{pH}$ with final $\mathrm{pH}$. A plot of $\mathrm{pH}$ discrepancies versus the initial $\mathrm{pH}$ was constructed and the point of zero charge was obtained from the values which cuts the $\mathrm{X}$-axis.

\section{Results and Discussion}

\subsection{The effect of initial dye concentration on the photocatalytic efficiency of $\mathrm{C} \mathrm{N}$ co- doped $\mathrm{TiO}_{2}{ }^{-} \mathrm{P} 25$}

The effect of initial dye concentration on the photocatalytic efficiency of PU1-350 sample is shown in Figure 1. As expected, the photocatalytic activity of RR4 dye decreased with increasing RR4 dye concentration where the highest photocatalytic activity occurred for $5 \mathrm{mg} \mathrm{L}^{-1}$ concentration of RR4 dye solution. Pseudo first order rate constants for the photocatalytic degradation of different concentration of RR4 dye by PU1-350 photocatalyst were $0.290,0.235,0.160$ and $0.085 \mathrm{~min}^{-1}$ for 5 , $10,15,30$ and $60 \mathrm{mg} \mathrm{L}^{-1}$ respectively. Accordingly, this is due to the color of the solution that becomes more intense with increasing concentration. Photons from the light irradiation were absorbed by the dye molecules rather than by $\mathrm{TiO}_{2}$ particles which caused the light-screening effect that retarded the penetration of light into the surface of the photocatalyst and this eventually decreased the efficiency of the photocatalyst and thereby reduced the formation of $\mathrm{OH} \bullet$ and $\mathrm{O}_{2} \bullet$ radicals.

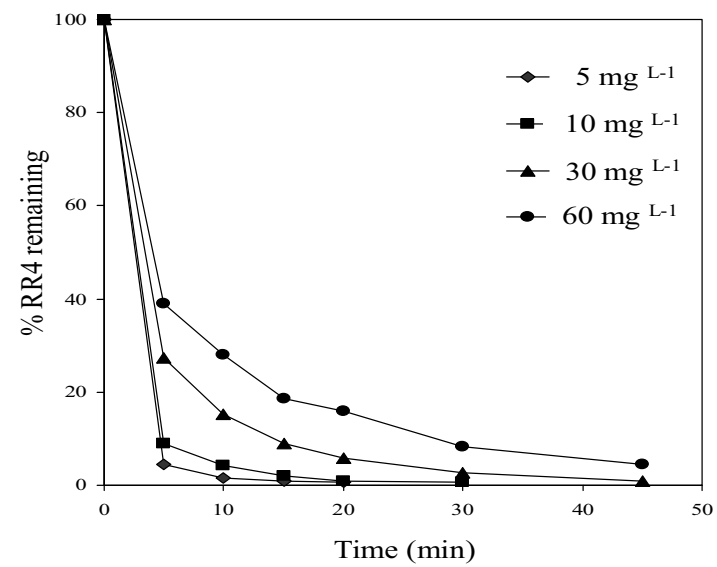

Figure 1. Photocatalytic degradation at different initial concentration of $\mathrm{RR} 4$ using $\mathrm{C} \mathrm{N}$ co-doped $\mathrm{TiO}_{2}{ }^{-} \mathrm{P} 25$ sample (PU1-350). 


\subsection{Effect of catalyst loading on the photocatalytic efficiency of $\mathrm{C} \mathrm{N}$ co-doped $\mathrm{TiO}_{2}{ }^{-} \mathrm{P} 25$}

Figure 2 shows the rate of the photocatalytic degradation of $30 \mathrm{mgL}^{-1} \mathrm{RR} 4$ dye by various amount of $\mathrm{C}$ N co-doped $\mathrm{TiO}_{2}{ }^{-} \mathrm{P} 25$ (PU1-350) loading under a $45 \mathrm{~W}$ compact fluorescent lamp. As observed with TC1-560 and PP0.6-450, the degradation rate of RR4 dye by PU1-350 increased with increasing catalyst loading until $0.04 \mathrm{~g}$ beyond which the rate began to be slightly reduced (Figure 2 ). The increasing rate of RR4 removal for the loading of 0.012 to $0.04 \mathrm{~g}$ PU1-350 catalyst was due to increasing amount of PU1-350 particles in the system. By increasing the PU1-350 particles, the number of photon and the dye molecules absorbed on the surface of the active site would also increase which eventually caused the photocatalytic activity of PU1-350 to increase. However, by further increasing the amount of PU1-350 beyond $0.04 \mathrm{~g}$, the rate decreased instead of becoming constant. There are two possibilities that influence this phenomenon might be due to the scattering of light and reduction in light penetration through the solution as a result of the excess catalyst particles and the aggregation of $\mathrm{TiO}_{2}$ particles at high concentration which caused a decrease in the number of surface active sites, thus bringing little stimulation to the catalytic reaction [13].

\subsection{Effect of aeration flow rate on the photocatalytic efficiency of $\mathrm{C} \mathrm{N}$ co-doped $\mathrm{TiO}_{2}$ P25}

Aeration was supplied continuously to the solution throughout the experiment by using an aquarium air pump as the source of aeration. The presence of air bubbles from the aeration in the system promoted a significance agitation of the aqueous suspension for homogeneous distribution of the catalyst in the solution and to provide oxygen for the oxidative photocatalytic degradation. Figure 3 shows the effect of flow rates towards photocatalytic degradation of RR4 dye using $\mathrm{C} N$ co-doped $\mathrm{TiO}_{2}{ }^{-} \mathrm{P} 25$ (PU1-350) as photocatalyst. It was found that $25 \mathrm{~mL} \mathrm{~min}{ }^{-1}$ was the optimum aeration rate for a (PU1-350) where the the degradation rate of RR4 was almost two times faster than the system running without aeration (stirring process) with pseudo first order rate constant (k) for $25 \mathrm{~mL} \mathrm{~min}^{-1}$ aeration and stirring process ca. 0.058 and $0.027 \mathrm{~min}^{-1}$ respectively. All photocatalytic and adsorption experiments in this work were therefore carried out under this optimum aeration rate.

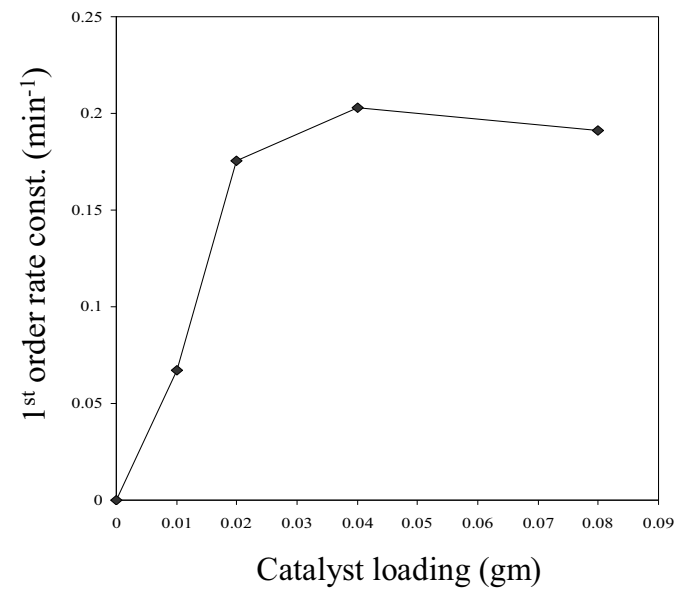

Figure 2. Photocatalytic degradation of RR4 dye by different amount of PU1-350 loading irradiated with a 45 Watt fluorescent lamp.

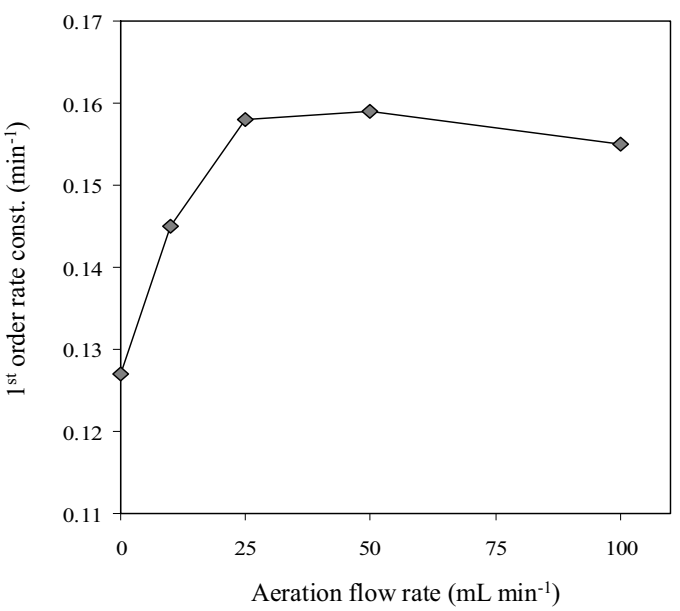

Figure 3. Effect of aeration flow rate on the photocatalytic degradation of RR4 under a $45 \mathrm{~W}$ fluorescent lamp. 


\subsection{Effect of initial pH of the RR4 dye solution on the photocatalytic efficiency of C N co-doped $\mathrm{TiO}_{2}{ }^{-\mathrm{P} 25}$}

Figure 4a shows the rate of the photodegradation of RR4 under $\mathrm{C} \mathrm{N}$ co-doped $\mathrm{TiO}_{2}{ }^{-} \mathrm{P} 25$ (PU1-350) at different $\mathrm{pH}$ conditions as a function of the irradiation time. The results indicated that the highest rate of photocatalytic degradation of RR4 was within the range of $\mathrm{pH} 2-7$ while at $\mathrm{pH} 10$, the rate was significantly slower where less than $30 \%$ of RR4 removed after 10 minutes of irradiation. Slower photocatalytic degradation of RR4 at $\mathrm{pH} 10$ was due to the repulsion between the dye molecules and PU1-350 particles which led to decreased adsorption efficiency. The photocatalytic degradation of RR4 became faster at $\mathrm{pH} 2-7$ due to the PZC value for PP0.6-450 to be c.a. 4.5 (Figure $4 \mathrm{~b}$ ) thus making it's particles to be positively charged with less agglomeration thus increased adsorption process.
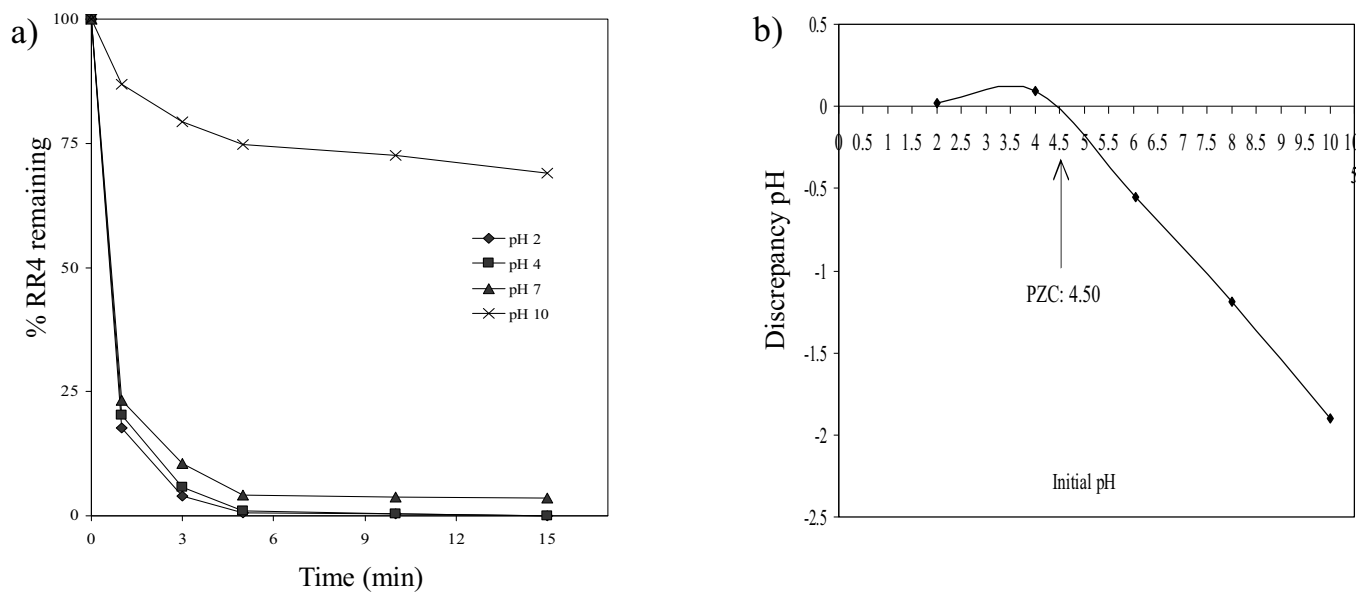

Figure 4. a) Photocatalytic degradation at different $\mathrm{pH}$ of RR4 dye under PP0.6-450 sample irradiated with 45 Watt fluorescent lamp, and b) Point of zero charge for $\mathrm{C} \mathrm{N}$ co- doped $\mathrm{TiO}_{2}{ }^{-} \mathrm{P} 25, \mathrm{PU} 1-350$.

\section{Conclusion}

The irradiation of $\mathrm{C} \mathrm{N}$ co-doped $\mathrm{TiO}_{2}$ was conduct using four parameters namely initial concentration, effect of loading, effect of aeration flow rate and effect of $\mathrm{pH}$. It can be observed the photocatalytic activity of RR4 dye decreased with increasing RR4 dye concentration where the highest photocatalytic activity occurred for $5 \mathrm{mg} \mathrm{L}^{-1}$ meanwhile $0.04 \mathrm{~g}$ of catalyst loading give optimum photocatalytic degradation. It was found that $25 \mathrm{~mL} \mathrm{~min}^{-1}$ was the optimum aeration rate for a (PU1-350). Effect of $\mathrm{pH}$ was conducted based on the optimum loading and conclude that the photocatalytic degradation of RR4 became faster at $\mathrm{pH} 2$ - 7 due to the PZC value for PP0.6-450 to be c.a. 4.5. This research studies will generate towards the green technology that can be destructive the wastewater especially from dyes industries. This parameters study can be proved that $\mathrm{C} N$ co-doped $\mathrm{TiO}_{2}$ can be purify contaminated water in various situation. For the future work, the modification of doping with others element like non-metal or metal with $\mathrm{C} \mathrm{N}$ co-doped $\mathrm{TiO}_{2}$ can be increase the efficiency of photodegradation under visible light. Moreover, the immobilized technique can be used in future to overcome the difficulty of filtration on suspension.

\section{References}

[1] M.T. Yagub, T K. Sen, S. Afroze and H.M. Ang, Dye and its removal from aqueous solution by adsorption: A review, Adv. Colloid. Interface. Sci., 209, 172-184, (2014). 
[2] V. Vaiano, O. Sacco, D. Sannino and P. Ciambelli, Nanostructured N-doped $\mathrm{TiO}_{2}$ coated on glass spheres for the, Appl. Catal. B., 170-171, 153-161, (2015).

[3] M.A. Nawi, and S.S. Sheilatina, Photocatalytic decolourisation of reactive red 4 dyes by an immobilised TiO2/chitosan layer by layer system, J. Colloid Interface Sci., 372, 80-87, (2012).

[4] T.K. Tseng, Y.S. Lin, Y.J. Chen and H. Chu, A review of photocatalysts prepared by sol-gel method for VOCs removal, Int. J. Mol. Sci., 11, 2336-2361, (2010).

[5] J. Yuan, M. Chen, J. Shi and W. Shangguan, Preparation and photocatalyst hydrogen evolution of N-doped TiO2 from urea and titanium tetrachloride, Int. J. Hydrogen Energy, 31, 1326-1331, (2006).

[6] P. Li, G. Zhao, K. Zhao, J. Gao and T. Wu, An efficient and energy saving approach to photocatalytic degradation of opaque high-chroma methylene blue wastewater by electrocatalytic pre-oxidation, Dye Pigments, 92, 923-928, (2012).

[7] J.P. Michael, W.D. Charles and P.P. Ivan, N-doped $\mathrm{TiO}_{2}$ visible light photocatalyst films via a sol- gel route using TMEDA as the nitrogen source, J. Photochem. Photobiol. A., 281, 27-34, (2014).

[8] X. Hou, C.W. Wang, W.D. Zhu, X.Q. Wang, Y. Li, J. Wang, J.B. Chen, T. Gan, H.Y. Hu and F. Zhou, Preparation of nitrogen-doped anatase $\mathrm{TiO}_{2}$ nanoworm/nanotube hierarchical structures and its photocatalytic effect, Solid State Sci., 29, 27-33, (2014).

[9] D. Chen, Z. Jiang, J. Geng, Q. Wang and D. Yang, Carbon and nitrogen co-doped $\mathrm{TiO}_{2}$ with enhanced visible-light photocatalytic activity, Ind. Eng. Chem. Res., 46, 2741-2746, (2007).

[10] W.I. Nawawi and M.A. Nawi, Carbon coated nitrogen doped P25 for the photocatalytic removal of organic pollutants under solar and low energy visible light irradiations, J. Mol. Catal, A: Chem., 383-384, 83-93, (2014).

[11] S.H. Shin, H.H. Chun and W.K. Jo, Enhanced photocatalytic efficiency of N-F-co-embedded titania under visible light exposure for removal of indoor-level pollutants, Materials, 8, 31-41, (2015).

[12]N. R. C. Fernandes MacHado and V. S. Santana, Influence of thermal treatment on the structure and photocatalytic activity of $\mathrm{TiO}_{2} \mathrm{P} 25$, Today, 107-108, 595-601, (2005).

[13] M.I. Badawy, F.El. Gohary, M.Y. Ghaly and M.E.M. Ali, Enhancement of olive mill wastewater biodegradation by homogeneous and heterogeneous photocatalytic oxidation, J. Hazard. Matter., 169, 673-679, (2009). 